Center for Research on Economic and Social Theory

and

Department of Economics

Working Paper Series

Competitive Coupon Targeting

Greg Shaffer and Z. John Zhang

May 1994

Number 94-02

DEPARTMENT OF ECONOMICS

University of Michigan

Ann Arbor, MI 48109-1220

SUIMER AND LAURA

POSTER LIBRARY

단 I 3 1994 


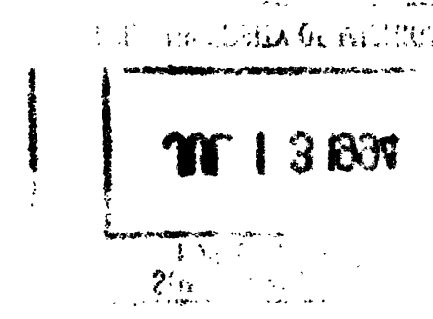




\section{Competitive Coupon Targeting}

\author{
Greg Shaffer* \\ Department of Economics \\ University of Michigan \\ Ann Arbor, MI 48109-1220
}

and

Z. John Zhang

John M. Olin School of Business

Washington University in St. Louis

St. Louis, MO 63130

First Version: August 1992

This Version: May 1994

\section{Abstract}

With the advent of panel data on household purchase behavior, and the development of statistical procedures to utilize this data, firms can now target coupons to selected households with increasing accuracy and cost effectiveness. As a consequence, new avenues of competition have opened up in which firms play an active role in market segmentation. In this article, we develop an analytical framework to examine the effect of targeting on firm profits, prices, coupon face values, and redemption rates. We also determine firms' optimal mix of offensive and defensive couponing. Among our findings: when rival mix of oftencive firms can targe their coupon prouptions. Al brand switchers, the outcome will be a prisoner's dilemma in which the net effect of targeting is simply the cost
of distribution plus the discount given to redeemers.

\footnotetext{
-We thank John Hauser, two anonymous referees, and especially Scott Neslin for helpful sug-
} gestions that have improved this article.
Programs where promotions are tailored to the household are the way to go. I see the

mass media disappearing and the individual marketing becoming almost one on one.

\section{Introduction}

Firms are increasingly using coupons as a marketing tool to compete for price-sensitive consumers. During the 1980 's, the number of coupons distributed by consumer goods manufacturers grew at an average annual rate in excess of $11 \%$. Since then, the upward trend in coupon distribution has shown little sign of abating. According to NCH (1992), an all time high 292 billion coupons, more than 3000 coupons per household, were distributed in 1991.

One reason why firms compete for price-sensitive consumers by offering coupons instead of simply lowering the price of their product is that coupons engender market segmentation whereas lower regular prices do not. In essence, coupons facilitate third-degree price discrimination because only those consumers that present a coupon at the point of sale receive a discount; all other consumers pay the full price. ${ }^{2}$ As pointed out by Narasimhan (1984), Levedahl (1984), Sweeney (1984), Houston and Howe (1985), and others, such discrimination can be profitable as long as coupon users as a group have more elastic demand and/or lower reservation prices than non-coupon users. ${ }^{3}$ In each instance, an implicit assumption in the literature is that firms distribute coupons randomly via the mass-media, e.g. free standing inserts in newspapers, and rely on consumer self-selection to achieve market segmentation.4

Owing to recent advances in information technologies that have led to a growing sophistication 'Frank Woodard, marketing director for Vons Cos., as quoted by Millstein (1989).

${ }^{2}$ Coupons may serve other objectives as well. For instance, they may be used to motivate retail participation in price promotions (Gerstner and Hess, 1991a,b). For a complete list of managerial objectives served by coupons, see the excellent survey by Blattberg and Neslin (1990).

${ }^{3}$ Narasimhan (1984) not only endogenously derives differences in consumer willingness to use coupons based on exogenous differences in income, he also provides empirical evidence to support the claim that coupon users are indeed

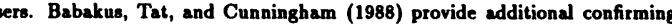
'In addition to the use of coupons, there are several other instances in the price discrimination literature in which firms structure their pricing to induce consumer self-selection. For example, in Salop (1977), differences in buyer search costs are exploited by a multi-store monopolist charging a distribution of prices. Differences in buyers' inventory holding costs motivate firms' temporary price cuts in Jeuland and Narasimhan (1985), etc. 
in coupon targeting capabilities, firms need no longer rely exclusively on consumer self-selection to discriminate in price. With the advent of panel data on household purchase behavior, and the development of statistical procedures to utilize this data, firms can now target coupons to selected households with increasing accuracy and cost effectiveness. ${ }^{5}$ As a consequence, new avenues of competition have opened up in which firms can play a much more active role in market segmentation.

Many analysts predict that targeted promotions are the wave of the future and will gradually replace mass-media distribution. As an example of what is already possible, some marketing firms and retail chain stores have co-initiated card-based programs in which plastic identification/check cashing cards (e.g. Catalina Marketing Co's Checkout Direct) are distributed to individuals for use when buying goods. Transactions are then entered into a database each time a customer uses the card. ${ }^{6}$ Over time, the database can be accessed to provide targeted coupons based on the customer's history of purchasing behavior. ${ }^{7}$ In addition to point-of-purchase programs, coupons can also be distributed via direct-mail, thereby enabling firms to target consumers not only on the basis of past purchasing behavior, but also on self-reported survey data such as demographic and lifestyle characteristics. ${ }^{8}$

The ongoing revolution in coupon targeting capabilities obviously has important implications for firm rivalry and competition. Our purpose in this paper is to develop an analytical framework to address several issues. First, what is the relationship between coupon targeting programs and random mass-media distribution? Will the former replace the latter over time, as some believe, or are the two complementary? Second, how does the ability to target coupons to individual a purchase behavior is to develop statistical procedures capable of generating household-level estimates of parameters given the relatively small amount of data per household. See the

'In many cases, the data is stored and updated right on the 'smart' card. This is the case, for instance, with Advanced Promotion Technologies'

' tually to sell time series data on the purchases of approximately $\mathbf{4 0}$ million American households. See Mayer (1990). ${ }^{\circ}$ For example, Computerized Marketing Technologies, Inc. mails individualized UPC coded coupons to 15 million households three times a year (Business Week 1989). Similarly, Donnelly Marketing targets 30 million household through its Carol Wright program (Raphel 1988a). households affect regular prices and coupon face values? Does the answer depend on whether firms are also distributing coupons via the mass-media? Third, do rivalrous firms stand to gain or lose from the increasing sophistication of coupon targeting? Fourth, what types of coupon targeting strategies can be expected to emerge in a competitive environment? That is, what fraction of coupons should be sent to rivals' customers (offensive targeting) in an effort to increase sales, and what fraction of coupons should be sent to own customers (defensive targeting) in an effort to preempt rivals' coupon promotions?

Our framework posits a spatial model of product differentiation and assumes that data on past purchasing behavior has given firms knowledge regarding the approximate location of each consumer in brand space. Thus, in our model, the ability to target coupons permits firms to discriminate in price according to consumer heterogeneity in brand loyalty. ${ }^{9}$ While this opens up a new avenue of competition among firms, it does not preclude the traditional price discrimination that arises with consumer self-selection. Whereas targeting coupons to specific households exploits differences in customer brand loyalty, random coupon distribution coupled with consumer self-selection exploits differences in coupon user/non-user price sensitivity. Both types of price discrimination can coexist.

After controlling for the effects of mass-media coupon distribution, we find that coupon targeting intensifies competition without allowing firms profitably to raise their regular prices. Thus, the outcome of rivalrous coupon targeting is a prisoner's dilemma in which profits are lower for all firms. This supports the contention of some that the net effect of couponing in a competitive environment is simply the cost of distribution plus the discount given to redeemers (Raphel 1988b; and Chiang 1992). Our results also provide some support for the view that coupons should be directed at a rival's customers for the purpose of increasing brand sales (Neslin and Clarke 1987; and Neslin 1990). ${ }^{10}$ This strategy does indeed predominate in equilibrium, if the cost of targeting is high. On the other hand, the model predicts that as the cost of coupon targeting declines over 9Heterogeneity in brand loyalty is the sine qua non of sales promotions in Narasimhan (1988). ${ }^{10}$ By ascribing a central role to a firm's incremental sales per redemption, these authors implicitly assume that targeting a rival's customers is best provided the cost of such targeting is not too steep. 
time, relatively more and more defensive targeting will be implemented.

The rest of the paper is organized as follows. Section II specifies the model and notation. In section III, we derive equilibrium coupon targeting strategies assuming that firms selectively target coupons to individual consumers. After controlling for the effects of mass-media coupon distribution, section IV considers the impact of competitive coupon targeting on firm profits, prices and coupon face values. Section $V$ examines the incidence of offensive and defensive targeting and section VI derives comparative statics concerning the effect a declining cost of coupon targeting over time has on the incidence of coupon redemption rates, incremental sales per redemption, and the number of coupons distributed. Section VII concludes.

\section{The Model and Notation}

Consider a market in which two firms sell competing brands of a consumer good that is produced at constant marginal cost $c$. Since heterogeneity in consumer tastes is essential to study coupon targeting, we adopt a spatial model of product differentiation and assume, a la Hotelling (1929), that consumer tastes differ along a single dimension in product space. For simplicity, we abstract from product design choices by locating firms at opposite ends of the line segment $[0,1] .{ }^{11}$

We consider a two-stage game-theoretic model of pricing and coupon distribution. In the initial stage, firms compete for customers by simultaneously and noncooperatively choosing their regular prices $\left(R_{A}, R_{B}\right)$ and coupon face values. Once pricing and promotion depth decisions have been made, firms proceed in stage two by distributing coupons according to their targeting strategies $\left(\Omega_{A}, \Omega_{B}\right)$, which specify the probability that consumers on any given interval of the line segment $[0,1]$ will receive a firm's targeted coupon. Firms may also randomly distribute coupons via the mass-media in stage two. If so, these coupons are assumed to reach all consumers with probability one. We use subgame perfection as our solution concept which means that the actions chosen in 11The location of the firms is exogenously specified solely to simplify the exposition. Our qualitative conclusion continue to hold for any symmetric pair of firm locations on $[0,1]$ for which a pure strategy Nash pricing equilibrium exists (see appendix E). each stage are required to be Nash given the choices in the preceding stages, and the choices in the early stages are chosen knowing the effects of such actions in the stages to follow. ${ }^{12}$

This two-stage game accentuates the strategic role of firms' coupon targeting decisions by assuming they are made subsequent to decisions on regular prices and coupon face values. From a game theoretic point of view, an implicit assumption is that this two-step decision making sequence corresponds to the relative speed with which these choices are typically altered in practice. Hence, firm pricing and promotion depth decisions are thought of as strategic managerial decisions that are relatively less responsive than perturbations in coupon targeting strategies.

A similar multi-stage sequence is also employed by Rao (1991) in modeling firms' price promotion decisions in a competitive environment. Although he focuses on the frequency of firms' price promotions, whereas we focus on firms' coupon targeting decisions, his multi-stage sequence in which regular prices and promotion discounts are chosen prior to the frequency of promotion is analogous to our set-up. Beyond providing a convenient framework of analysis, however, there is anecdotal evidence, offered by Rao, that some managers do make their price promotion decisions in such a sequence. Ultimately, however, stylized models such as ours should be judged on the usefulness of their insights and the validity of the testable implications they generate. ${ }^{13}$

\section{Consumers and the spatial model framework}

We now turn attention to the consumer side of the model. In particular, we posit that consumers differ in their willingness to pay for the two brands. The farther away a consumer's tastes are from the product characteristics of a given brand, the less the consumer is willing to pay. Let $V$ be a common reservation price for each consumer's ideal brand and let $t^{i}$ be the transportation cost per unit of distance for a consumer of type $i$. Then a type $i$ consumer located at $X$ is willing to ${ }^{12}$ See Moorthy (1985) for his excellent survey on marketing applications using subgame perfection. is It is encouraging to note that our analysis is robust to alternative sequences of play in which regular prices and coupon face values are chosen prior to coupon distribution strategies. Unfortunately, we are unable to check the robustness of our results for games in which coupon distribution strategies and coupon lace values are chosen request). Moreover, solving for mixed strategy equilibria when the mixing can occur over a continuum of coupon distribution straterien, coupon face valuese end posesibly reguler prices is beyond current game-theoretic techniques. 
pay $V-t^{i} X$ for brand A located at zero, and $V-t^{i}(1-X)$ for brand B located at one. In order to focus on coupon targeting in a competitive environment, we assume $V$ is sufficiently large that within the relevant range of prices, all consumers will make a purchase.

Consumers also differ in their willingness to redeem coupons. A fraction $\alpha^{c}$ of consumers incur no costs of coupon usage. Anyone in this group who receives a firm's coupon will redeem it if she purchases from the firm. To simplify the exposition, these consumers will henceforth be known as C-Users. Coupon usage for everyone else is prohibitively costly. These consumers will henceforth be known as Non-Users. Following convention, we assume that $C$-Users as a group are weakly more price-sensitive than Non-Users. In our spatial framework, this means that $t^{c}$, the transportation cost for $C$-Users, is less than or equal to $t^{n}$, the transportation cost for Non-Users.

The marginal consumer among Non-Users is defined as the consumer who is just indifferent between buying from either one of the two firms given $\left(R_{A}, R_{B}\right)$. Algebraically, the location of such a consumer must satisfy $R_{A}+t^{n} X=R_{B}+t^{n}(1-X)$. Solving yields

$$
\bar{X}=\frac{R_{B}-R_{A}+t^{n}}{2 t^{n}} .
$$

All Non-Users who are located to the left of $\bar{X}$ will buy from firm A, while all Non-Users located to the right of $\bar{X}$ will buy from firm B. Note that in the event both firms have equal regular prices, $\bar{X}=1 / 2$, and Non-Users simply buy whichever brand is closer to their specific tastes.

Of even more interest is the purchasing behavior of the $C$-Users. Define $P_{i}$ as the price $C$-Users must pay to purchase firm $i$ 's product if they do not have its targeted coupon. In the event firm $i$ does not also randomly distribute coupons via the mass-media, this price is the same as firm $i$ 's regular price. Otherwise, $P_{i}$ is interpreted as firm $i$ 's regular price minus the face value of its massmedia coupons, which all $C$-Users receive. Under either interpretation, the marginal consumer in the set of $C$-Users who do not receive a targeted coupon is located at

$$
\tilde{X}=\frac{P_{B}-P_{A}+t^{c}}{2 t^{c}} \text {. }
$$

Those in the set who are located to the left of $\tilde{X}$ will buy from firm A, while those in the set who are located to the right of $\tilde{X}$ will buy from firm B. At equal prices, consumers in this group buy whichever brand is closer to them in product space.

Some $C$-Users, however, will receive one or both firms' targeted coupons. As a prelude to determining who they might be, define $d_{i}$ as the net value of firm $i$ 's targeted coupon. In the event firm $i$ does not also randomly distribute coupons, $d_{i}$ is interpreted as the actual face value of firm i's targeted coupon. Otherwise, $d_{i}$ is interpreted as the amount by which firm $i$ 's targeted coupon face value exceeds firm i's mass-media coupon face value. It is now possible to distinguish between four types of $C$-Users based upon their expected purchasing behavior given $\left(P_{A}, P_{B}, d_{A}, d_{B}\right)$. Consumers with strong preferences for brand $A$ will prefer buying from firm $A$ even if they have B's targeted coupon and do not have A's targeted coupon. Algebraically, the location of such a consumer satisfies $P_{A}+t^{c} X \leq P_{B}-d_{B}+t^{c}(1-X)$. This inequality implies all $C$-Users located to the left of

$$
X_{A}=\frac{P_{B}-P_{A}-d_{B}+t^{c}}{2 t^{c}},
$$

will buy brand $A$. There is no need for firm $A$ ever to target these consumers. Intuitively, in the event $P_{B}=P_{A}, X_{A} \geq 0$ requires $d_{B} \leq t^{c}$, which means that the discount offered by firm B falls short of the disutility these consumers would incur if they were to purchase brand $B$.

Similarly, consumers with strong preferences for brand B will prefer buying from firm B even if they have A's targeted coupon and do not have B's targeted coupon. Algebraically, the location of such a consumer must satisfy $P_{A}-d_{A}+t^{c} X \geq P_{B}+t^{c}(1-X)$. This inequality implies that all $C$-Users located to the right of

$$
X_{B}=\frac{P_{B}-P_{A}+d_{A}+t^{c}}{2 t^{c}},
$$

will buy brand B. There is no need for firm B ever to target these consumers. As above, the intuition is most easily seen in the symmetric case where $P_{A}=P_{B}$. Note that in this case, $X_{B} \leq 1$ requires that $d_{A} \leq t^{c}$.

The remaining $C$-Users might potentially be induced to switch brands as a consequence of 
coupon targeting. Define firm A's potential brand switchers as those consumers without strong preferences for brand $A$ in the sense that they lie outside the interval $\left[0, X_{A}\right]$, but who nevertheless will buy from firm A conditional on having firm A's targeted coupon, regardless of whether they have a targeted coupon from firm B. Algebraically, a consumer located at $X \geq X_{A}$ is a potential brand switcher if and only if $P_{A}-d_{A}+t^{c} X \leq P_{B}-d_{B}+t^{c}(1-X)$. Thus, firm A's potential brand switchers are located at $X_{A} \leq X \leq X_{S}$, where

$$
X_{S}=\frac{P_{B}-P_{A}+d_{A}-d_{B}+t^{c}}{2 t^{c}} .
$$

Intuitively, $C$-Users located between $X_{A}$ and $X_{S}$ are consumers whose preferences for brand $A$ are relatively weak. In the absence of firm A's targeted coupon, they can be induced to buy brand $B$ if they have B's targeted coupon. With equal prices and coupon face values, $X_{S}$ is located at $1 / 2$.

Analogously, define firm B's potential brand switchers as those consumers lying outside the interval $\left[X_{B}, 1\right]$, who will buy from firm $B$ conditional on having firm $B$ 's targeted coupon, regardless of whether they have a targeted coupon from firm A. Algebraically, firm B's potential brand switchers are described by the set of locations $X_{S} \leq X \leq X_{B}$.

The relative locations of the four $C$-User types are well-ordered, although the exact positions are contingent on the regular prices and coupon face values chosen by the firms. When coupled with the location of the marginal consumer among $C$-Users who do not receive a targeted coupon, i.e. $\tilde{X}$, there are five distinct regions where $C$-Users exhibit different purchasing behaviors as depicted in figure 1.

Figure 1: C-User Locations in Product Space

\begin{tabular}{llllllll} 
I & & II & III & IV & V \\
\hline & $X_{A}$ & & $\tilde{X}$ & $X_{S}$ & $X_{B}$ & & 1
\end{tabular}

Figure 1 has been drawn assuming $d_{A}>d_{B}>0$. An analogous figure can be drawn if $d_{B}>$ $d_{A}>0$. If $d_{B}$ were to equal zero, $\tilde{X}-X_{A}=X_{B}-X_{S}=0$, and hence regions II and IV would have zero width. If, in addition, $d_{A}$ were to equal zero, $X_{S}-\tilde{X}=0$, and region III would also have zero width. If instead, $d_{A}=d_{B}>0$, only region III would have zero width.

\section{Competitive Coupon Targeting}

In this section, we derive the stage-two equilibrium targeting strategies for each firm after controlling for possible mass-media distribution. In practice, the targeting information available to firms comes from historical data on household purchasing behavior as well as from information gleaned from market surveys. ${ }^{14}$ For instance, Rossi and Allenby (1993) report on a scanner panel dataset which consists of observations on individual household purchases of tuna dating back two and a half years. Using newly developed statistical procedures, they show how the data can be used to rank households according to brand preference and price sensitivity. In our model, we abstract from data estimation problems and simplify by assuming firms can perfectly distinguish between $C$-Users with different purchasing behaviors.

Assuming a constant marginal cost of coupon targeting, $z$, neither firm will ever target coupons to the set of Non-Users, since these consumers do not redeem coupons, and neither firm will ever target coupons to the set of $C$-Users in regions I and $\mathrm{V}$, since these consumers cannot be induced to switch brands given each firm's discount. The rest of the $C$-Users, however, are potential brand switchers. These are the consumers over whom rivalry in targeted coupon promotion will occur.

Consider first a representative $C$-User in region II. This consumer will only buy from firm B if she receives B's targeted coupon and does not receive $A$ 's targeted coupon. Otherwise, she will buy from firm $A$. Whether or not firm $A$ wants to target a coupon to this consumer depends upon "Catalina Marketing, Citicorp P.O.S. Information Services, and Advanced Promotion Technologies have been
working with retailers on developing electronic couponing, working with retailers on developing electronic couponing, whereby manufacturers' coupons can be targeted to conthe testing stage of gathering data to the implementation of widescale target couponing programs. With jump advent of electronic couponing, increasingly complex targeting strategies will become feasible as the technology improves and information on household purchasing behavior accumulates. 
firm B's coupon targeting strategy and vice versa. For instance, firm A will not want to target its coupon to this consumer if firm B does not target its coupon to her, since all $C$-Users in region II who do not receive B's coupon will buy from A even without A's coupon. But if firm A does not target its coupon to her, firm B will want to target her, so as to induce her to switch brands. Given that each firm's targeting strategy is chosen simultaneously, it is clear from the above discussion that no stage-two pure strategy Nash equilibrium exists for $C$-Users in region II. There does exist, however, a unique mixed strategy Nash equilibrium.

To simplify the exposition, we henceforth restrict the admissable range of each firm's net targeted coupon face value such that $d_{i} \geq 0$; otherwise, $C$-Users will not redeem them. Furthermore, for all $d_{i}>0$, we assume $d_{i}<R_{A}-c-z$ to ensure that firm $i$ would rather target its coupon and make a sale than not target and not make a sale. This upper bound on $d_{i}$ is without loss of generality, since firm $i$ can still signal its intention not to target coupons in stage two (if it wishes) by choosing $d_{i}=0$ in stage one.

Define $C_{i}^{\prime \prime}(X)$ as firm i's pure strategy "target coupons to $C$-Users at $X \in\left[X_{A}, \bar{X}\right]^{n}$ and let $\bar{C}_{i}^{I I}(X)$ denote firm i's pure strategy "do not target coupons to $C$-Users at $X \in\left[X_{A}, \bar{X}\right]$." Then the normal form game between firms $\mathrm{A}$ and $\mathrm{B}$ for $\mathrm{C}$-Users in region II is given in figure 2 below.

\section{Figure 2: Coupon Targeting in Region II}

$C_{B}^{I I}$

$C_{B}^{I I}$

\begin{tabular}{l|c|c|}
\hline$C_{A}^{\prime \prime}$ & $\left(P_{A}-d_{A}-c-z\right),-z$ & $\left(P_{A}-d_{A}-c-z\right), 0$ \\
\hline$\tilde{C}_{A}^{\prime \prime}$ & $0,\left(P_{B}-d_{B}-c-z\right)$ & $\left(P_{A}-c\right), 0$ \\
\hline
\end{tabular}

The first payoff in each cell corresponds to firm A's payoff and the second corresponds to firm B's payoff. For instance, consider the upper-left cell in figure 2. This corresponds to a situation in which both firms target their coupons in region II. In this case, all $C$-Users will buy brand A. Thus, firm A's per-unit profit in this cell is equal to $\left(P_{A}-d_{A}-c-z\right)$. Firm B's per-unit profit loss in this cell is equal to its marginal cost of coupon targeting. In the lower-right cell in figure 2, neither firm targets coupons in region II. Once again, all C-Users will buy brand A. Firm A's per-unit profit in this cell is equal to $\left(P_{A}-c\right)$. Firm B's per-unit profit in this cell is zero. In the off-diagonal cells in figure 2, only the firm that targets in region II earns positive profit. Solving for the unique mixed strategy equilibrium profile (see appendix A) yields $\left(\sigma_{A}^{*}, \sigma_{B}^{*}\right)$, where

$$
\sigma_{A}^{*}\left(C_{A}^{I I}\right)=\frac{P_{B}-d_{B}-c-z}{P_{B}-d_{B}-c}, \quad \sigma_{B}^{*}\left(C_{B}^{I I}\right)=\frac{d_{A}+z}{P_{A}-c}
$$

are the respective probabilities that firms $A$ and $B$ target coupons in region II. ${ }^{15}$

Firm A prefers not to target coupons to $C$-Users in this region, since they are already predisposed to buy from A. Nonetheless, it practices defensive couponing because otherwise firm B would target coupons to them with probability one. Firm B is aggressive in this region. At a marginal cost $z$ for every coupon delivered, it takes a chance on being able to attract new customers. On balance, however, firm B succeeds in attracting brand switchers only with probability $\sigma_{B}^{*}\left(1-\sigma_{A}^{*}\right)$, since its offensive couponing is tempered somewhat by firm A's defensive couponing strategy.

Intuitively, the probability that firm A targets coupons to C-Users in region II is positively related to firm B's net per unit markup, since the higher is firm B's markup, the more tempting it is for firm B to target coupons, and hence the more defensive couponing firm A must do to retain its customers. The probability that firm B targets coupons in this region is positively related both to the marginal cost of couponing and to firm A's targeted coupon face value. The more firm A's cost of defending its customers increases, the more tempting it is for firm $A$ to forego targeting, and hence the more attractive is firm B's offensive couponing. Notice it is possible for C-Users in ${ }^{15}$ There are two distinct ways to interpret each firm's mixed strategy. One can think of firm i's mixing in region II as an all or nothing coupon drop that occurs with probability $\sigma_{i}^{*}\left(C_{i}^{I \prime}\right)$ or does not occur with probability $\left(1-\sigma_{i}^{*}\left(C_{i}^{I}\right)\right)$. Alternatively, one can think of firm $i$ as randomly selecting a fraction $\sigma_{i}^{(}\left(C_{i}^{I I}\right)$ of $C$. sers in region II to target. Under
the former interpretation, couponing emerges endogenously as an occasional price reduction phenomena. Under the latter interpretation, coupons are continuously available to a fraction of consumers. 
this region to have zero, one, or two targeted coupons. An immediate implication when $C$-Users have both is that the redemption rate for targeted coupons is necessarily less than one. ${ }^{16}$

Region IV is symmetric to region II. $C$-Users in this region will buy from firm $A$ if they receive A's targeted coupon and do not receive B'B targeted coupon. Otherwise, they will buy from firm B. Whether or not firm B targets coupons in this region depends on firm A's coupon targeting strategy and vice versa. Just as in region II, it is easy to verify that there is no stage-two pure strategy Nash equilibrium in this region. Solving for the unique mixed strategy equilibrium profile yields $\left(\tilde{\sigma}_{A}, \tilde{\sigma}_{B}\right)$, where

$$
\tilde{\sigma}_{A}\left(C_{A}^{l V}\right)=\frac{d_{B}+z}{P_{B}-c}, \quad \tilde{\sigma}_{B}\left(C_{B}^{l V}\right)=\frac{P_{A}-d_{A}-c-z}{P_{A}-d_{A}-c},
$$

are the respective probabilities that firms $A$ and $B$ target coupons in region IV. Analogous to region II, firm B would prefer not to target coupons to C-Users in this region. Nonetheless, it does so to mitigate the effectiveness of firm A's offensive couponing. On balance, firm A succeeds in attracting brand switchers only with probability $\tilde{\sigma}_{A}\left(1-\tilde{\sigma}_{B}\right)$.

It is easy to verify that firm A (B) always (never) targets coupons to C-Users in region III. Intuitively, these consumers will buy from firm $A$ if and only if they have A's targeted coupon; hence, it is not surprising that a pure strategy Nash equilibrium exists in this region.

To summarize, each firm's equilibrium coupon targeting strategy for a given region $r$ in brand space is as follows:

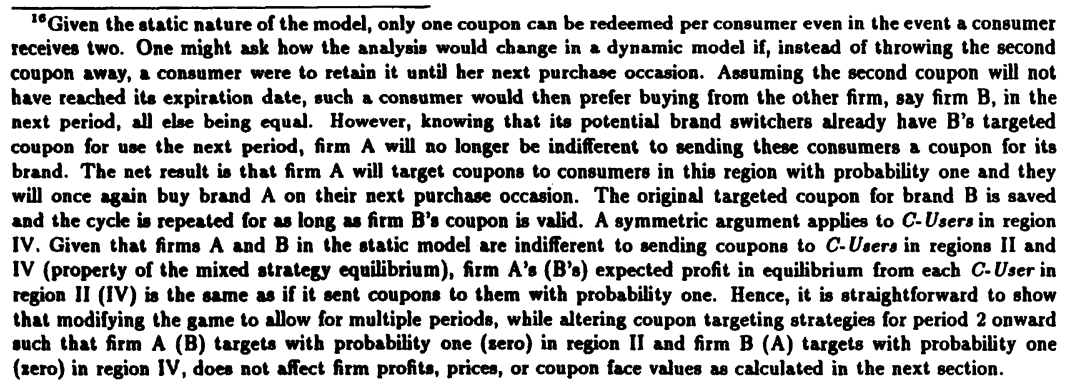

(2ero) in ferm A (B) targets with probability one (sero) in region II and firm B (A) targets with probability on (2ero) in region IV, does not affect firm profits, prices, or coupon face values as calculated in the next section.

$$
\Omega_{A}(r)=\left\{\begin{array}{cl}
0 & \text { if } \mathrm{r}=\mathrm{I}, \mathrm{V} \\
\sigma_{A}^{*}\left(C_{A}^{I I}\right) & \text { if } \mathrm{r}=\mathrm{II} \\
1 & \text { if } \mathrm{r}=\mathrm{III} \\
\tilde{\sigma}_{A}\left(C_{A}^{I V}\right) & \text { if } \mathrm{r}=\mathrm{IV}
\end{array} \quad \Omega_{B}(r)=\left\{\begin{array}{cl}
0 & \text { if } \mathrm{r}=\mathrm{I}, \mathrm{V} \\
\sigma_{B}^{*}\left(C_{B}^{I I}\right) & \text { if } \mathrm{r}=\mathrm{II} \\
0 & \text { if } \mathrm{r}=\mathrm{III} \\
\tilde{\sigma}_{B}\left(C_{B}^{I V}\right) & \text { if } \mathrm{r}=\mathrm{IV}
\end{array} .\right.\right.
$$

We conclude the analysis in this section by summing each firm's expected profit over all $C$-Users given $\Omega_{A}$ and $\Omega_{B}$. While this may seem an arduous task because of the induced brand switching in regions II and IV, the summation is simplified by noting that in any mixed strategy equilibrium, each player is indifferent between mixing or playing one of its pure strategies. In our model, this means that firm $A$ 's expected profit in equilibrium from each $C$-User in region II is equal to the profit it would receive from playing $C_{A}^{I I}$, i.e. $\left(P_{A}-d_{A}-c-z\right)$, and firm $B$ 's expected profit in equilibrium from each $C$-User in region II is equal to the profit it would receive from playing $\bar{C}_{B}^{I}$, i.e. zero. Similarly, firm B's expected profit from each $C$-User in region IV is $\left(P_{B}-d_{B}-c-z\right)$, while firm A's expected profit from each $C$-User in region IV is zero.

Firm B's profit from each $C$-User in regions I and III is zero, while firm A's profit from each $C$-User in regions I and III is $\left(P_{A}-c\right)$ and $\left(P_{A}-d_{A}-c-z\right)$ respectively. Firm B earns $\left(P_{B}-c\right)$ from each $C$-User in region $\mathrm{V}$, while firm $A$ 's profit in this region is zero. Assuming a uniform distribution of consumers over $[0,1],{ }^{17}$ and summing expected profits over all consumers yields

$$
\begin{gathered}
\Pi_{A}^{*}=\left(1-\alpha^{c}\right)\left(R_{A}-c\right) \bar{X}+\alpha^{c}\left(\left(P_{A}-c\right) X_{S}-\left(d_{A}+z\right)\left(X_{S}-\max \left\{X_{A}, 0\right\}\right)\right) \\
\Pi_{B}^{*}=\left(1-\alpha^{c}\right)\left(R_{B}-c\right)(1-\bar{X})+\alpha^{c}\left(\left(P_{B}-c\right)\left(1-X_{S}\right)-\left(d_{B}+z\right)\left(\min \left\{X_{B}, 1\right\}-X_{S}\right)\right)
\end{gathered}
$$

Firm A's overall profit is equal to its profit from Non-Users plus its profit from $C$-Users in regions I, II, and III. Similarly, firm B's overall profit is equal to its profit from Non-Users plus its profit from C-Users in regions IV and V. Note that firm B's offensive couponing in region II yields no gain, while firm A's expected profit in this region is somewhat dissipated relative to what it would ${ }^{17}$ This assumption allows us to derive explicit solutions for subsequent comparative static analysis. We discuss in appendix D the sense in which our main propositions are robuat to non-uniform customer distributions. 
be in the absence of B's targeting threat. Similarly, firm A's offensive couponing in region IV yields no gain, while firm B's expected profit in this region is somewhat dissipated. Thus, whether coupon targeting is profitable in equilibrium turns on whether firms can raise prices to Non-Users and to $C$-Users in regions I and $\mathrm{V}$ by more than enough to offset the expected loss in profit from the discounts given to C-Users in regions II, III, and IV

\section{Prices, Coupon Face Values, and Profit}

We address several issues in this section: (a) do rival firms stand to gain or lose from the increasing sophistication of coupon targeting programs, (b) how does the ability to target coupons to individual households affect regular prices and coupon face values, and (c) what is the relationship between coupon targeting programs and traditional mass-media distribution. In the process, we hope to shed light on two polar views regarding the effects of couponing in a competitive environment.

One view is that coupons effectively sort consumers into groups with differing elasticities of demand. Relative to a uniform price, firms raise price to the non-coupon users and, by way of the discount, lower price to the coupon users. Intuition from the literature on oligopolistic thirddegree price discrimination, e.g. Borenstein (1985) and Holmes (1988), suggests this type of market segmentation will be profitable even if market demand does not increase. ${ }^{18}$

An opposing view is that the outcome of couponing in a competitive environment is a prisoner's dilemma in which all firms lose. According to this view, each firm's couponing succeeds only in maintaining market share and, as a result, profits for each firm fall by an amount equal to the cost of distribution plus the discount given to redeemers. This view rejects the traditional price discrimination motive for coupons by implicitly assuming firms do not recover the cost of their couponing activities with higher regular prices. ${ }^{19}$

${ }^{18}$ Borenstein (1985) considers a spatial model in which consumers are located on a circle. Sorting consumers into binary groups by reservation prices, he finds that for any given number of firms, third-degree price discrimination always leads to higher profits. Holmes (1989) considers a symmetric duopoly model with general demand. In his finds that profits always rise with third-degree price discrimination when market demand is held constant. ${ }^{19}$ In their survey chapter on coupons, Blattberg and Neslin $(1990: 271,272)$ summarize this view as follows: "The
Our analysis proceeds by examining these views in the context of two scenarios. In the first (second) scenario, we consider the competitive effects of coupon targeting in the absence (presence) of mass-media distribution. In doing so, we isolate the effects of targeted couponing after controlling for the standard consumer self-selection story with mass-media distributed coupons.

Assume initially that the cost of distributing coupons via the mass-media is prohibitive and focus exclusively on market segmentation induced by targeted couponing. In this case, $P_{i}=R_{i}$, and $d_{i}$ is interpreted as firm $i$ 's targeted coupon face value. Proceeding back to the first stage, each firm chooses its regular price and targeted coupon face value to maximize its second stage equilibrium profit. Thus, firm i's problem is to choose $\left(R_{i}, P_{i}, d_{i}\right)$ to maximize $\Pi_{i}^{*}$ such that $P_{i}=R_{i}$ and $d_{i} \geq 0$. Assuming $t^{c}>t^{n} / 2$ and simultaneously solving the Kuhn-Tucker conditions of both maximization problems yields the unique subgame perfect equilibrium regular prices and targeted coupon face values as functions of the exogenous parameters $z$ and $t .^{20}$ The solution, given in figure 3 below, is derived in appendix B. We simplify notation by defining $t^{w}=t^{n} t^{c} /\left(\left(1-\alpha^{c}\right) t^{c}+\alpha^{c} t^{n}\right)$ and interpreting it as a weighted average of the transportation costs of C-Users and Non-Users. It is easily verified that $t^{c} \leq t^{w} \leq t^{n}$

Figure 3: Targeted couponing in the absence of mass-media distribution.

\begin{tabular}{|c|c|c|c|c|}
\hline Cost Ratio & Regular Price & \multicolumn{2}{|c|}{ Promotion Decisions } & Profit \\
$z / t^{w}$ & $R_{A}=R_{B}$ & $P_{A}=P_{B}$ & $d_{A}=d_{B}$ & $\Pi_{A}^{*}=\Pi_{B}^{*}$ \\
\hline$\frac{z}{t^{w}} \geq 1$ & $t^{w}+c$ & $t^{w}+c$ & 0 & $\frac{t^{w}}{2}$ \\
$\frac{z}{t^{w}}<1$ & $t^{w}+c$ & $t^{w}+c$ & $\frac{t^{\omega}-z}{2}$ & $\frac{t^{w}}{2}-\frac{\left.\alpha^{c}\left(t^{w}\right)^{2}-z^{2}\right)}{B t^{c}}$ \\
\hline
\end{tabular}

Discussion of the intuition and implications of figure 3 is best left until after the solution is strategic problem faced by the manufacturer is that its market share is vulnerable to the couponing activities of its compelition. However, this view is shared by both manufacturers, so both end up using coupons and succeed in protecting their market share, but have eroded their profits by incurring the costs of couponing." ${ }^{20}$ The restriction on $C$-User transportation costs ensures that regions $I$ and $V$ are non-empty. For $t^{c} \leq t^{n} / 2$, one
can show the existence of equilibria in which all $C$-Users are potential brand switchers. Coupon targeting in this case can show the existence of equilibria in which all $C$.Users are potentia
merely mimics mass-media couponing with little additional insight. 
given to the second scenario (figure 4). This will enable us to economize on the exposition as many of the insights are robust across the two situations.

We now proceed to consider the polar case in which distributing coupons via the mass-media is costless. In this case, $P_{i}$ is interpreted as firm $i$ 's regular price minus the face value of its massmedia coupon, and $d_{i}$ is interpreted as the amount by which firm $i$ 's targeted coupon face value exceeds firm $i$ 's mass-media coupon face value. Each firm's problem in stage one is now modified by replacing the constraint $P_{i}=R_{i}$ with $R_{i} \geq P_{i}$. Thus, firm i's problem is to choose $\left(R_{i}, P_{i}, d_{i}\right)$ to maximize $\Pi_{i}^{*}$ such that $R_{i} \geq P_{i}$ and $d_{i} \geq 0$. The unique subgame perfect equilibrium, given in figure 4 below, is derived in appendix $C$.

Figure 4: Targeted couponing in the presence of mass-media distribution.

\begin{tabular}{|c|c|c|c|c|}
\hline \begin{tabular}{c|c|c|} 
Cost Ratio \\
$z / t^{c}$
\end{tabular} & Regular Price & \multicolumn{2}{|c|}{ Promotion Decisions } & Profit \\
\hline$R_{A}=R_{B}$ & $P_{A}=P_{B}$ & $d_{A}=d_{B}$ & $\Pi_{A}^{*}=\Pi_{B}^{*}$ \\
$\frac{z}{t^{c}} \geq 1$ & $t^{n}+c$ & $t^{c}+c$ & 0 & $\frac{\left(1-\alpha^{c}\right)^{n}}{2}+\frac{\alpha^{c} t^{c}}{2}$ \\
$\frac{z}{t^{c}}<1$ & $t^{n}+c$ & $t^{c}+c$ & $\frac{t^{c}-z}{2}$ & $\frac{\left(1-\alpha^{c}\right) t^{n}}{2}+\frac{\alpha^{c}\left(3\left(t^{c}\right)^{2}+z^{2}\right)}{8 t^{c}}$ \\
\hline
\end{tabular}

Comparing equilibria in figures 3 and 4 , we begin with the left-most column titled Cost Ratio. This is the ratio formed by dividing the marginal cost of coupon targeting by the average transportation cost of all users ( $C$-Users) in figure $3(4)$. In each figure, the first two rows delineate the conditions under which coupon targeting will $\left(d_{i}>0\right)$ or will not occur $\left(d_{i}=0\right) .{ }^{21}$ Intuitively, one would expect coupons not to be targeted if the marginal cost of coupon targeting exceeds the price-cost markup on individual sales to $C$-Users, since inducing brand switching (or defending market share) under such circumstances is never profitable. To verify this intuition, note that the price-cost markup in figure 3 is $R_{A}-c=t^{w}$ and that the no targeting condition is indeed $z \geq t^{w}$. Analogously, since mass-media coupons are assumed distributed to all $C$-Users in figure ${ }^{21}$ Recall that regions II, III, and IV have zero width when $d_{A}=d_{B}=0$.
4, the price-cost markup to these consumers in the absence of targeting is $P_{A}-c=t^{c}$ and the no targeting condition is $z \geq t^{c}$. Several marketing implications can now be deduced by interpreting the transportation cost parameter as a measure of average consumer brand loyalty. ${ }^{22}$

Proposition 1 For a given z, coupon targeting emerges in equilibrium if and only if firms compete in markets where average consumer brand loyalty exceeds a critical level.

An immediate implication is that firms in markets where consumer brand loyalty is relatively weak, i.e. low product differentiation, will not target coupons. Firms in these markets (e.g. $t^{w}<z$ in figure 3) compete on price alone because per-unit price-cost markups are too small for coupon targeting to be profitable. By analogous reasoning, firms in markets where competing brands are highly differentiated target coupons because although it is expensive to induce consumers to switch brands, per-unit price-cost markups are very large. ${ }^{23}$

Turning to the second column in figures 3 and 4, titled Regular Price, and comparing rows 1 and 2, it is seen that firms do not raise regular prices to Non-Users even when they can target coupons to potential brand switchers. Moreover, in the first column under the heading Promotion Decisions in figure 4 , it is seen that the discounted prices paid by $C$-Users who do not have a targeted coupon are also unaffected.

Proposition 2 Regular prices and mass-media coupon face values are unchanged after the introduction of coupon targeting.

In equilibrium, some of the targeting is designed to keep one's own potential brand switchers (defensive) and some of the targeting is designed to steal the rival's potential brand switchers (offensive). As a result, the division of the market becomes blurred. Each firm lures away a fraction of the rival's brand switchers with the net effect being to increase the area of competition ${ }^{22}$ One can also think of the transportation cost parameter as a measure of product differentiation in the market since at $t=0$ the products are perfect substitutes and as $t$ increases the products become less substitutable. whroposition 1 contrasts with proposition 1 in haju et a (1990), who find that firms do not price promote when consumer brand loyalty is sufficiently large. In their model, price promotions cannot be targeted. 
from a single point in the middle of brand space to the interval $X_{B}-X_{A}$. The enhanced competition prevents firms from profitably charging higher prices to their more brand loyal customers. ${ }^{24}$

These findings do not contradict the usual coupon price discrimination story since comparing across rows in figures 3 and 4 shows that the introduction of mass-media couponing does lead to higher prices to the Non-Users. The reason is that random coupon distribution coupled with consumer self-selection leads to an exogenous market segmentation which exploits differences in coupon user/non-user price sensitivity. By contrast, the introduction of coupon targeting allows firms to discriminate in price according to heterogeneity in consumer brand loyalty and, given the play of $\left(\Omega_{A}, \Omega_{B}\right)$, leads to endogenous market segmentation. It is endogenous in the sense that the number of $C$-Users in sections $\mathrm{I}$ and $\mathrm{V}$ is a function of both firms' regular prices and coupon face values which are chosen in stage one. Thus, if a firm contemplates raising its regular price to these consumers, it risks exposing a fraction of them to its rival's targeted coupon in stage two. ${ }^{25}$ In equilibrium, coupon targeting has no effect on regular prices.

To summarize, both coupon targeting and mass-media coupon distribution can coexist. The latter is associated with higher regular prices and is profitable for the firms; the former simply increases competition for the potential brand switchers and is deleterious to firm profits.

Proposition 3 Coupon targeting in a competitive environment gives rise to a prisoner's dilemma in which profits are lower for both firms.

Since coupon targeting is very effective in stealing a rival's potential brand switchers and keeping one's own, each firm stands to gain by availing itself of the targeting technology regardless of its ${ }^{24}$ Formally, one can think of $\left(R_{A}, R_{B}\right)$ as jointly determining $\bar{X}$ and $\left(P_{A}, P_{B}\right)$ as jointly determining $\tilde{X}$. These boundary points of marginal consumers separate firm $A$ 's customers from firm $B$ 's customers in the absence of targeted coupon distribution. But they also serve the same role when coupons are targeted since, in equilibrium, $d_{A}=d_{B}$ and coupons $X_{s}=X=X$. Thus ${ }^{25}$ The endogeneity of market segmentation is critical in constraining firms from raising their regular prices when coupons are targeted. In contrast, Narasimhan (1988), who considers a duopoly model in which consumers are either captive brand loyal and not price-sensitive at all, or brand switchers and willing to shop around, finds that when firms distribute coupons (redeemed only by brand switchers), prices rise to the non-coupon users (captive loyal customers). Market segmentation is not endogenous in his setting however, because the number of captive brand loyal customers is assumed fixed. rival's strategy. But firms are caught in a prisoner's dilemma. Although some consumers are induced to switch brands, expected market shares do not change. And since regular prices do not rise with the introduction of targeting, the net effect of this form of couponing in a competitive environment is simply the cost of distribution plus the discount given to redeemers.

We now consider how coupon face values and the loss in profit with targeting vary with massmedia distribution, average consumer brand loyalty, and the marginal cost of coupon targeting. Turning to the fourth column in figures 3 and 4, titled Profit, and comparing rows 1 and 2, the change in profit with the introduction of coupon targeting is given by

$$
\frac{\alpha^{c}\left(z^{2}-\left(t^{k}\right)^{2}\right)}{8 t^{c}}<0
$$

where $k=w$ in the absence of mass-media distribution and $k=c$ in the presence of mass-media distribution. Since $t^{w} \geq t^{c}$, the loss in profit from the introduction of coupon targeting is weakly greater in the absence of mass-media distribution. The reason is that the additional discount given to $C$-Users in regions II and IV when they already have a mass-media coupon, i.e. $\left(t^{c}-z\right) / 2$ from the second column under the heading Promotion Decisions in figure 4, is less than the targeted discount they would receive if there were no mass-media coupon, i.e. $\left(t^{w}-z\right) / 2$ from figure 3

Intuitively, the size of $d_{i}$ endogenously determines the set of potential brand switchers. In particular, $d_{i}$ determines the number of firm i's potential brand switchers. Although each firm tries to steal its rival's customers, its expected profit from doing so is zero. Instead, firms earn positive expected profit from their defensive targeting. From firm i's perspective, the marginal profit of a customer who is prevented from switching to firm $j$ is $t^{k}-z-d_{i}$. Since the interval of firm i's potential brand switchers is $d_{i} / 2 t$, firm i will choose $d_{i}$ to maximize $\left(t^{k}-z-d_{i}\right) d_{i} / 2 t$. This yields $d_{i}=\left(t^{k}-z\right) / 2$. Notice that $d_{i}$ is proportional to the marginal profit from retaining a $C$-User, which means it is increasing in average consumer brand loyalty. Not surprisingly, higher coupon face values are needed to induce switching as the brands become more differentiated.

When coupons are not also distributed via the mass-media, $d_{i}$ is interpreted as the actual 
targeted coupon face value. However, when coupons are in addition distributed via the massmedia, the actual targeted coupon face value is given by $R_{i}-P_{i}+d_{i}=t^{n}-\left(t^{c}+z\right) / 2$. Comparing actual targeted coupon face values across scenarios gives

$$
t^{n}-\frac{\left(t^{c}+z\right)}{2} \geq t^{w}-\frac{\left(t^{c}+z\right)}{2}=\frac{\left(2 t^{w}-t^{c}\right)-z}{2} \geq \frac{\left(t^{w}-z\right)}{2},
$$

which implies that targeted coupon face values are weakly higher (strictly higher if $t^{n}>t^{c}$ ) in the presence of mass-media coupon distribution than in its absence. This finding simply reflects the fact that regular prices are higher when mass-media coupons are also distributed and hence C-Users must be given a larger targeted discount.

One might think that a lower marginal cost of couponing targeting would benefit the firms. This is not the case, however, since a lower cost of couponing induces higher equilibrium targeted coupon face values, which in turn increases the width of regions II and IV thereby leading to an increase in the number of coupons distributed. This chain of events also has adverse implications regarding the redemption rate and number of incremental sales as will be seen in section VI.

\section{Offensive and Defensive Targeting}

The allure of the new targeted forms of couponing is obvious; they can be used to attract rival firms' potential brand switchers. The idea is that some consumers may be induced to purchase what would otherwise be a less preferred brand for them simply because they have received that brand's coupon. Since a firm stands to gain to the extent that its coupons can generate incremental sales in this manner, it would seem that firms should target their coupons offensively. Indeed, this is the advice routinely offered in the literature. For instance, Alsop (1985) recommends that coupons be mailed directly to competitive brand users, Blattberg and Neslin (1990) note that manufacturers can place their coupons in magazines more likely to be read by a rival's customers, and Rossi and Allenby (1993) suggest that firms may want to target coupons to households "that show loyalty toward other brands and yet are price sensitive."
These prescriptions are not convincing in a competitive context, however, as coupon targeting can also serve to defend market share by preventing a rival firm's coupon promotion from luring away one's own potential brand switchers. Thus, it may seem surprising that our analysis strongly concurs with the offensive minded intuition, provided the cost of coupon targeting is relatively high (as is presently the case). On the other hand, our analysis further suggests that as the marginal cost of coupon targeting falls over time, firms should gradually decrease their efforts to attract brand switchers and instead shift more towards defending against the loss of their existing customers.

To see this, substitute equilibrium $\left(P_{A}, P_{B}\right)$ and $\left(d_{A}, d_{B}\right)$ when $z<t^{k}$ into $\left(\Omega_{A}, \Omega_{B}\right)$. This gives the probability that a firm targets offensively as

$$
\sigma_{B}^{*}\left(C_{B}^{I I}\right)=\tilde{\sigma}_{A}\left(C_{A}^{I V}\right)=\frac{t^{k}+z}{2 t^{k}},
$$

and the probability that a firm targets defensively as

$$
\sigma_{A}^{*}\left(C_{A}^{I I}\right)=\tilde{\sigma}_{B}\left(C_{B}^{I V}\right)=\frac{t^{k}-z}{t^{k}+z} .
$$

To reduce the dimensionality of these targeting incidences, let the marginal cost of coupon targeting be expressed as a fraction of the transportation cost, i.e. $z=f t^{k}$, where $0 \leq f \leq 1$. The incidence of offensive and defensive targeting can now be depicted in figure 5 below with $f$ on the horizontal axis and the probability of targeting on the vertical axis.

Proposition 4 Firms should predominantly target offensively when the cost of coupon tangeting is high and adjust their mix by implementing relatively more defensive targeting as this cost falls.

As the cost of coupon targeting decreases, stealing a rival's customers and defending one's own customers becomes more attractive. If its rival were to continue to practice the same (or less) incidence of defensive targeting, a firm would target offensively with certainty. Knowing this, firms implement relatively more defensive targeting to defend their market share. In equilibrium, the amount of offensive targeting actually decreases given the intensity of defensive couponing. Exactly 
Figure 5: Incidence of Offensive and Defensive Targeting

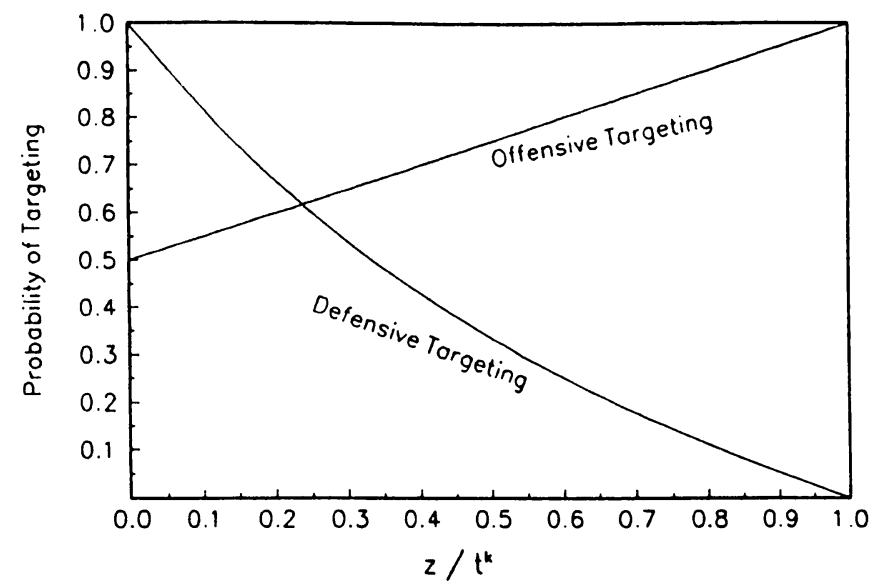

the same intuition applies when average consumer brand loyalty increases, since stealing a rival's customers and defending one's own becomes more attractive the higher are equilibrium regular prices. The managerial prescription is summarized below.

Proposition 5 Firms should implement relatively more defensive targeting the higher is average consumer brand loyalty in their industry.

\section{Comparative Statics}

In their survey chapter on coupons, Blattberg and Neslin (1990) provide a very useful framework to assess the profitability of a firm's coupon promotion taking as given coupon face values and prices as well as the rival's coupon distribution strategy. Their method weighs the incremental gains engendered by a firm's coupon promotion against its associated incremental costs. In addition to the number of coupons distributed, two other variables of interest stand out. One is the coupon redemption rate. The other is incremental sales per redemption, defined as the fraction of redemptions that are from customers who would not have bought the firm's product had they not received its coupon. In this section, we derive comparative statics concerning how these important variables change across markets with differing degrees of average consumer brand loyalty and over time as the marginal cost of coupon targeting falls.

\section{Number of Targeted Coupons Distributed}

The number of targeted coupons distributed by each firm depends on the width of regions II and IV and on the incidence of offensive and defensive targeting. It is given by

$$
N=\left[\left(X_{S}-X_{A}\right) \sigma_{A}^{*}+\left(X_{B}-X_{S}\right) \tilde{\sigma}_{A}\right]=\frac{\left(t^{k}-z\right)\left(3\left(t^{k}\right)^{2}+z^{2}\right)}{8\left(t^{k}\right)^{2}\left(t^{k}+z\right)} .
$$

It is easily verified that $N$ is decreasing in $z$ and increasing in $t^{k}$. Intuitively, the greater is the marginal cost of coupon targeting relative to average consumer brand loyalty, the smaller is the net gain from inducing a rival firm's $C$-User to switch brands. Hence, firms simply have less incentive to target coupons when $z$ is high and when $t^{k}$ is low.

\section{Targeted Coupon Redemption Rate}

Since defensively targeted coupons are always redeemed and offensively targeted coupons are redeemed only if a $C$-User does not also have a defensive coupon, the number of targeted coupons redeemed per firm is equal to the incidence of each firm's defensive targeting times the number of its potential brand switchers plus the incidence of each firm's offensive targeting times the probability that its rival does not target defensively times the number of its rival's potential brand switchers Thus, each firm's targeted coupon redemption rate is given by

$$
R=\frac{\left[\left(X_{S}-X_{A}\right) \sigma_{A}^{*}+\left(X_{B}-X_{A}\right) \tilde{\sigma}_{A}\left(1-\tilde{\sigma}_{B}\right)\right]}{N}=\frac{2\left(\left(t^{k}\right)^{2}+z^{2}\right)}{3\left(t^{k}\right)^{2}+z^{2}} .
$$

Each firm's targeted coupon redemption rate is increasing in $z$ and decreasing in $t^{k}$. Intuitively, since C-Users are presumed to incur no cost of coupon usage, the only reason why each firm's targeted coupon redemption rate would be less than one is if some $C$-Users receive targeted coupons from 
both firms. This occurs more frequently the greater is the overlap between offensive and defensive targeting. Referring to figure 5 , the overlap is seen to be higher with low $z\left(\right.$ high $\left.t^{k}\right)$. Hence, targeted coupon redemption rates increase with the marginal cost of coupon targeting and decrease with average consumer brand loyalty.

\section{Targeted Incremental Sales per Redemption}

Each firm's targeted incremental sales, defined as the decrease in sales that would occur if the firm defected from equilibrium by not targeting coupons, is equal to the number of consumers who have received both targeted coupons plus the number of offensively targeted coupons that are redeemed. Thus, each firm's targeted incremental sales per redemption is given by

$$
I=\frac{\left[\left(X_{S}-X_{A}\right) \sigma_{A}^{*} \sigma_{B}^{*}+\left(X_{B}-X_{S}\right) \tilde{\sigma}_{A}\left(1-\tilde{\sigma}_{B}\right)\right]}{R}=\frac{\left(t^{k}+z\right)^{2}}{2\left(\left(t^{k}\right)^{2}+z^{2}\right)}
$$

Each firm's targeted incremental sales per redemption rate is increasing in $z$ and decreasing in $t^{k}$. Intuitively, the only reason why sales from targeted coupon redeemers would not be incremental is if some of a firm's potential brand switchers received only its targeted coupon. Since these consumers would have bought from it even in the absence of its coupon, they cannot be considered incremental. These non-incremental redemptions are more likely to occur the lower is the incidence of the rival firm's offensive targeting. Referring to figure 5, the incidence of a firm's offensive targeting is lower for low $z$ (high $t^{k}$ ). Hence, targeted incremental sales per redemption increase with the marginal cost of coupon targeting and decrease with average consumer brand loyalty. This comparative static result and the preceding ones are summarized in figure 6 below. In the figure, pluses (minuses) signify a positive (negative) relationship.

Proposition 6 Firms will distribute more targeted coupons, choose higher targeted coupon face values, experience lower targeted coupon redemption rates and achieve lower incremental sales per redemption the higher is average consumer brand loyalty in their industry.
Figure 6: Summary of comparative statics results

\begin{tabular}{|c|c|c|c|c|}
\hline \multirow{4}{*}{ Brand loyalty } & Face Value & Number Distributed & Redemption Rate & Incremental Sales \\
\cline { 2 - 5 } Cost of couponing & + & + & - & - \\
\hline
\end{tabular}

One might think that the incidence of targeting should be decreasing in average consumer brand loyalty, since inducing additional consumers to switch brands would become increasingly more expensive. Yet this factor is more than offset by the increasingly attractive per-unit pricecost markup; although the size of the discount needed to induce consumers to switch is increasing in average consumer brand loyalty, the regular prices that firms charge are increasing even more. As the incidence of targeting increases, however, consumers with multiple targeted coupons become more frequent and hence redemption rates fall. Incremental sales per redemption also fall as firms shift more toward defending their market share.

A similar pattern holds as the cost of coupon targeting falls. Firms adjust on the margin by increasing their coupon face value, though by less than the decrease in $z$, and taking advantage of the decrease in the cost of attracting brand switchers by increasing their incidence of targeting. Redemption rates and incremental sales per redemption fall for the same reason as above.

Proposition 7 Targeted coupon face values will increase, more targeted coupons will be distributed, targeted coupon redemption rates will decrease, and fewer redemptions will be incremental over time as the cost of coupon targeting falls.

Propositions 6 and 7 predict a negative association between targeted coupon face values and targeted coupon redemption rates, and between targeted coupon face values and targeted incremental sales per redemption, over time and across industries with varying consumer brand loyalty. 
At first blush, these predictions appear to be at odds with some established empirical literature which suggests the opposite is true. Based on observations from actual coupon drops, Reibstein and Traver (1982) and Ward and Davis (1978) find that higher coupon face values are associated with higher coupon redemption rates. Similarly, Klein (1985) and Shoemaker and Tibrewala (1985) find a positive relationship between coupon face values and incremental sales. In fact, these studies are demonstrating a functional relationship between two variables while holding other factors constant, whereas our predictions are based on equilibrium comparisons in which all factors vary simultaneously. To illustrate the difference in methods, and why there need be no contradiction, our predictions are fully consistent with the trend during the 1980's in which coupon face values increased in excess of the inflation rate while average coupon redemption rates uniformly declined. ${ }^{26}$

\section{Conclusion}

Our primary objective in this article has been to provide an analytical framework to investigate the competitive implications of the new forms of coupon targeting in which promotion discounts can be directed at brand switchers. In the process, we have compared and contrasted rivalry in price discrimination which leads to exogenous market segmentation, such as random coupon distribution coupled with consumer self-selection, with rivalry in price discrimination which leads to endogenous market segmentation, such as the new forms of coupon targeting. Our main result, after controlling for mass-media distribution, is that when coupons can be directed at brand switchers, the outcome is a prisoner's dilemma in which firms necessarily lose profit because regular prices do not increase.

We also derive managerial implications concerning the optimal mix of offensive and defensive targeting as well as several testable implications concerning the effects of coupon targeting on massmedia and targeted coupon face values, coupon redemption rates, incremental sales per redemption,

${ }^{26}$ A similar apparent paradox and resolution apply to the relationship between redemption rates and incremental sales. Intuition suggests a negative functional relationship between $R$ and $I$, since pure defensive targeting would achieve a $100 \%$ redemption rate but garner relatively few incremental sales, and a pure offensive targeting strategy would achieve a $10 \%$ incremental sales per redemplion bul have a low reden and a rale. However, his innilion holds equilibria, as in propositions 6 and 7 , yields different insights. and the overall number of coupons distributed. Unfortunately, the interpretation of past and presently available data is somewhat problematic because targeted and mass-media coupons have typically been mixed in the aggregate reported statistics and because the new forms of coupon targeting are so recent. Nevertheless, the decision by A.C. Neilson to track in-store coupons as a separate category for the first time in 1994 holds promise for future testing. For now, it is of some assurance to note that the number of coupons distributed during the 1980's increased dramatically, and that casual observation suggests current targeting strategies are primarily designed to induce brand switching. Both of these observations are consistent with the model's predictions.

Our framework consists of a relatively simple, stylized two-parameter model. Nevertheless, our main insights are robust to several modeling extensions as has been discussed previously. They include allowing the firms to locate symmetrically at any pair of locations on $[0,1]$, adding $d y$ namics to enable consumers to use unredeemed coupons on future purchase occasions, modifying the Hotelling linear demands by allowing for symmetric non-uniform customer distributions, and altering the sequence of play to have regular prices chosen first, followed by coupon face values and then targeting strategies.

Two extensions that we have not considered but which are nonetheless important are to allow for asymmetric customer distributions and to weaken firms' information sets regarding their knowledge of the approximate location of consumers in brand space. The first extension is necessary to investigate the relationship between targeted coupon promotions and firm size, particularly as it relates to market share. The second extension would help clarify the relationship between the two polar types of market segmentation considered in this article and, in addition, increase the scope of the analysis to include less accurate forms of targeting such as placing coupons in magazines more likely to be read by rivals' customers. 


\section{Appendix A}

Let $\left(\sigma_{A}\left(C_{A}^{I I}\right), \sigma_{B}\left(C_{B}^{\prime I}\right)\right)$ be a mixed-strategy equilibrium profile of the normal game given in figure 2, where $\sigma_{A}\left(C_{A}^{l l}\right)$ and $\sigma_{B}\left(C_{B}^{\prime I}\right)$ are the respective probabilities that firms $A$ and $B$ send coupons to C.Users in region II. Since in any such equilibrium a firm's mixed strategy makes its rival indifferent between its two pure strategies, $\left(\sigma_{A}\left(C_{A}^{I I}\right), \sigma_{B}\left(C_{B}^{I I}\right)\right)$ necessarily satisfy the following equations:

$$
-\sigma_{A}\left(C_{A}^{I I}\right) z+\left\{1-\sigma_{A}\left(C_{A}^{I I}\right)\right\}\left(P_{B}-d_{B}-c-z\right)=0,
$$$$
\left(P_{A}-d_{A}-c-z\right)=\left\{1-\sigma_{B}\left(C_{B}^{I I}\right)\right\}\left(P_{A}-c\right),
$$

where the left hand side of equation (1) (equation (2)) is firm B's (A's) expected payoff from targeting coupons in region II and the right hand side of equation (1) (equation (2)) is firm B's (A's) expected payoff from not targeting coupons in region II. The unique solution is given in the text.

\section{Appendix B}

In this appendix, we derive the unique subgame perfect equilibrium in the absence of mass-media coupons assuming $t^{c}>t^{n} / 2$. Our derivation consists of four parts. In part 1 , we characterize the necessary conditions for existence of an equilibrium in which $X_{A}>0$ and $X_{B}<1$. In part 2, we solve these necessary conditions and thereby identify a candidate equilibrium. In part 3 , we show that neither firm can profitably deviate and hence establish that the solution identified in part 2 is indeed a subgame perfect equilibrium. In part 4, we demonstrate uniqueness by proving there exists no other subgame perfect equilibrium.

Part 1: In the absence of mass-media coupons, firm $i$ chooses $R_{i}, P_{i}$, and $d_{i}$ by maximizing $\Pi_{i}^{*}$ as defined in section III such that $P_{i}=R_{i}$, and $d_{i} \geq 0$, taking its rival's choices as given. Substituting $R_{i}$ in for $P_{i}$, firm $i$ 's Lagrange function is given by $\mathcal{L}_{i}=\Pi_{i}^{*}+\lambda_{i} d_{i}$. Any subgame perfect equilibrium in which $X_{A}>0$ and $X_{B}<1$ can now be characterized by the following necessary first order conditions derived from each firm's constrained optimization:

$$
\frac{\partial \mathcal{L}_{A}}{\partial R_{A}}=\frac{1}{2 t^{w}}\left(R_{B}-2 R_{A}+c\right)+\frac{\alpha^{c}}{2 t^{c}}\left(d_{A}-d_{B}\right)+\frac{1}{2}=0,
$$

$$
\begin{aligned}
& \frac{\partial \mathcal{L}_{A}}{\partial d_{A}}=\frac{\alpha^{c}\left(R_{A}-2 d_{A}-c-z\right)}{2 t^{c}}+\lambda_{A}=0 \\
& \lambda_{A} d_{A}=0, \quad \lambda_{A} \geq 0, d_{A} \geq 0 \\
& \frac{\partial \mathcal{L}_{B}}{\partial R_{B}}=\frac{1}{2 t^{w}}\left(R_{A}-2 R_{B}+c\right)+\frac{\alpha^{c}}{2 t^{c}}\left(d_{B}-d_{A}\right)+\frac{1}{2}=0 \\
& \frac{\partial \mathcal{L}_{B}}{\partial d_{B}}=\frac{\alpha^{c}\left(R_{B}-2 d_{B}-c-z\right)}{2 t^{c}}+\lambda_{B}=0
\end{aligned}
$$$$
\lambda_{B} d_{B}=0, \quad \lambda_{B} \geq 0, d_{B} \geq 0
$$

It is easily verified that the second order conditions for constrained optimization are satisfied.

Part 2: Let $\left(\tilde{R}_{i}, \tilde{P}_{i}, \tilde{d}_{i}, \tilde{\lambda}_{i}\right)$ for $i=A, B$ satisfy conditions (3) to (8). The solution is derived by solving the following four Kuhn-Tucker cases:

Case 1: $\tilde{\lambda}_{A}>0$ and $\tilde{\lambda}_{B}>0$ (No Targeting): In this case, $\tilde{d}_{A}=\tilde{d}_{B}=0$ and, as can be verified, $\tilde{R}_{A}=\tilde{R}_{B}=\tilde{P}_{A}=\tilde{P}_{B}=t^{w}+c$. The $\tilde{\lambda}_{A}>0$ and $\tilde{\lambda}_{B}>0$ imply $t^{w}<z$.

Case 2: $\tilde{\lambda}_{A}=\tilde{\lambda}_{B}=0$ (Targeting): Solving equations (3), (4), (6), and (7) by setting $\lambda_{A}=\lambda_{B}=0$, we have $\tilde{R}_{A}=\tilde{R}_{B}=\tilde{P}_{A}=\tilde{P}_{B}=t^{w}+c$, and $\tilde{d}_{A}=\tilde{d}_{B}=\left(t^{w}-z\right) / 2$. Equations (5) and (8) imply $t^{w} \geq z$. Given $t^{c}>t^{n} / 2, X_{A}>0$ and $X_{B}<1$ are indeed satisfied.

Case 3: $\tilde{\lambda}_{A}>0$ and $\tilde{\lambda}_{B}=0$ : In this case, $\tilde{d}_{A}=0$. Solving equations (3), (6) and (7) gives:

$$
\begin{aligned}
& \tilde{R}_{A}=\tilde{P}_{A}=t^{w}+c+\frac{\alpha^{c} t^{w}\left(z-t^{\omega}\right)}{6 t^{c}-\alpha^{c} t^{w}}, \\
& \tilde{R}_{B}=\tilde{P}_{B}=z+c+\frac{6 t^{c}\left(t^{w}-z\right)}{6 t^{c}-\alpha^{c} t^{w}}, \\
& \tilde{d}_{B}=\frac{3 t^{c}\left(t^{w}-z\right)}{6 t^{c}-\alpha^{c} t^{w}} .
\end{aligned}
$$

However, $\tilde{d}_{B} \geq 0$ implies $t^{w} \geq z$ and $\bar{\lambda}_{A}>0$ implies, by equation (4), $t^{w}<z$. A contradiction.

Case 4: $\tilde{\lambda}_{A}=0$ and $\tilde{\lambda}_{B}>0$ : This case is symmetric to case 3 .

Thus, if a subgame perfect equilibrium exists in which $X_{A}>0$ and $X_{B}<1$, it is uniquely defined by cases 1 and 2 for the given parameter values therein.

Part 3: We now establish that the solution identified above is indeed a subgame perfect equilibrium. This is accomplished by showing that neither firm can profitably deviate. In particular, it must be that firm A (B) cannot profitably deviate such that $X_{A} \leq 0\left(X_{B} \geq 1\right)$. 
For $t^{w} \geq z$ and given $\tilde{R}_{B}=t^{w}+c$ and $\tilde{d}_{B}=\left(t^{w}-z\right) / 2$, firm A's optimal deviation such that $X_{A} \leq 0$ is given by:

$$
\left(\hat{R}_{A}, \hat{d}_{A}\right)=\arg \max _{R_{A}, d_{A}} \Pi_{A}^{*}\left(R_{A}, d_{A}, \tilde{R}_{B}, \tilde{d}_{B}\right) \quad \text { such that } \quad d_{A} \geq 0 \text { and } X_{A} \leq 0 .
$$

It is straightforward to show that $\hat{R}_{A}=\left(t^{w}+2 t^{c}+z\right) / 2+c$, and $\hat{d}_{A}=\left(t^{w}+2 t^{c}-z\right) / 4$, which implies $X_{A}=0$. Relaxing the constraint to allow $X_{A}>0$ as in case 2 above yields strictly higher profit. Hence, firm A's deviation is unprofitable. By symmetry, it is also never optimal for firm $B$ to deviate. Hence, the solution defined by case 2 is indeed a subgame perfect equilibrium for $t^{w} \geq z$. In the same way, it is straightforward to show that the solution given in case 1 defines a subgame perfect equilibrium for $t^{w}<z$.

Part 4: To establish uniqueness, we consider whether other subgame perfect equilibria exist. For instance, can there be an asymmetric subgame perfect equilibrium in which $X_{A} \leq 0$ and $X_{B} \leq 1$ ? If so, it is necessarily characterized by

$$
\begin{array}{lll}
\left(R_{A}^{\prime}, d_{A}^{\prime}\right)=\arg \max _{R_{A}, d_{A}} \Pi_{A}^{*}\left(R_{A}, d_{A}, R_{B}^{\prime}, d_{B}^{\prime}\right) \quad \text { such that } \quad d_{A} \geq 0 \text { and } X_{A} \leq 0, \\
\left(R_{B}^{\prime}, d_{B}^{\prime}\right)=\arg \max _{R_{B}, d_{B}} \Pi_{B}^{*}\left(R_{A}^{\prime}, d_{A}^{\prime}, R_{B}, d_{B}\right) \quad \text { such that } \quad d_{B} \geq 0 \text { and } X_{B} \leq 1 .
\end{array}
$$

It is straightforward, albeit arduous, to show that, for $t^{c}>t^{n} / 2$, the unique solution requires $X_{A}=0$ and no other constraints bind. However, at the candidate equilibrium, firm $A$ can profitably deviate so that $X_{A}>0$. The case where $X_{A} \geq 0$ and $X_{B} \geq 1$ is symmetric. Thus, it can be concluded that no asymmetric subgame perfect equilibrium exists.

We can similarly show that no subgame perfect equilibrium exists where $X_{A} \leq 0$ and $X_{B} \geq 1$. Since the proof is analogous, we spare readers the details. This completes our proof that, for $t^{c}>t^{n} / 2$, the unique subgame perfect equilibrium is defined in cases 1 and 2 .

\section{Appendix C}

In this appendix, we derive the unique subgame perfect equilibrium in the presence of mass-media coupons. Our derivation consists of four parts. In part 1 , we characterize the necessary conditions for existence of an equilibrium in which $X_{A}>0$ and $X_{B}<1$. In part 2, we solve these necessary conditions and thereby identify a candidate equilibrium. In part 3 , we show that neither firm can profitably deviate and hence establish that the solution identified in part 2 is indeed a subgame perfect equilibrium. In part 4, we demonstrate uniqueness by proving there exists no other subgame perfect equilibrium.

Part 1: In the presence of mass-media coupons, firm $i$ chooses $R_{i}, P_{i}$ and $d_{i}$ to maximize $\Pi_{i}^{*}$ such that $R_{i} \geq P_{i}$ and $d_{i} \geq 0$, taking its rival's choices as given. We can simplify the analysis considerably by observing that for $t^{n} \geq t^{c}$, the first constraint never binds for firm $i$. Incorporating this observation, the Lagrange function is again given by $\mathcal{L}_{i}=\Pi_{i}^{*}+\lambda_{i} d_{i}$. Any subgame perfect equilibrium in which $X_{A}>0$ and $X_{B}<1$ can now be characterized by the following necessary first order conditions derived from each firm's constrained optimization:

$$
\begin{aligned}
-2 R_{i}+R_{-i}+t^{n}+c & =0 \\
-2 P_{i}+P_{-i}+d_{i}-d_{-i}+t^{c}+c & =0 \\
\frac{\alpha^{c}\left(P_{i}-2 d_{i}-c-z\right)}{2 t^{c}}+\lambda_{i} & =0 \\
\lambda_{i} d_{i}=0, \quad \lambda_{i} \geq 0, & d_{i} \geq 0
\end{aligned}
$$

It is easily verified that the second order conditions for constrained optimization are satisfied.

Part 2: Let $\left(\tilde{R}_{i}, \tilde{P}_{i}, \tilde{d}_{i}, \tilde{\lambda}_{i}\right)$ for $i=A, B$ satisfy conditions (9) to (12). The solution is derived in the same way as in appendix $B$ and is given in figure 4.

Part 3: We now establish that the solution identified in figure 4 is indeed a subgame perfect equilibrium. This is accomplished by showing that neither firm can profitably deviate. In particular, it must be that firm $A$ (B) cannot profitably deviate such that $X_{A} \leq 0\left(X_{B} \geq 1\right)$. But this is trivial to show. Suppose $\hat{P}_{A}$ and $\hat{d}_{A}$ is firm A's optimal deviation in the $C$-User market such that $X_{A} \leq 0$. Then it must be the case that $\hat{d}_{A}=0$, for otherwise, if $\hat{d}_{A}>0$, firm $A$ could increase its profit by reducing its discounted price by this amount and not targeting coupons. However, $\hat{d}_{A}=0$ implies $X_{A}=X_{S}$ and therefore firm A's deviation profit from $C$-Users equals zero. Hence, it is not profitable for firm A to deviate. A similar analysis shows that firm $B$ will not deviate. 
Part 4: To establish uniqueness, one must show that no subgame perfect equilibria in which $X_{A} \leq 0$ or $X_{B} \geq 1$ exists. This is straightforward and utilizes the same logic in part 3 that proved there could be no profitable deviation by either firm.

\section{Appendix D}

In this appendix, we consider the robustness of the model to symmetric non-uniform customer distributions. Unfortunately, general conclusions are hard to reach since it is impossible to solve analytically for equilibrium $R_{i}, P_{i}$, and $d_{i}$. Nonetheless, we are able to show that for any symmetric non-uniform customer distribution, equilibrium firm profits necessarily decrease, and equilibrium regular prices do not change, in the neighborhood of $z$ for which coupon targeting just emerges in equilibrium. This provides support for the proposition that competitive coupon targeting does not allow firms profitably to raise price (proposition 2) and for the proposition that the outcome of targeting is a prisoner's dilemma (proposition 3).

Let $f(x)$ denote the distribution density function and $\mathcal{F}(x)$ the corresponding cumulative distribution function. We assume that $f(x)$ is continuous, differentiable, and symmetric over $[0,1]$. With these assumptions, it is trivial to verify that $f^{\prime}\left(\frac{1}{2}\right)=0$ and $\mathcal{F}\left(\frac{1}{2}\right)=\frac{1}{2}$. For simplicity, we consider only the case where mass-media couponing is absent and restrict attention to equilibria for which $X_{A}>0$ and $X_{B}<1$. All other assumptions in the paper remain unchanged.

Since a firm's targeting strategy is unaffected by the distribution density of consumers (see derivation in section III), the second stage equilibrium targeting strategies are given by $\left(\Omega_{A}, \Omega_{B}\right)$ as in the text. What differs with non-uniform customer distribution is the summation of consumers in each region, which yields non-linear demand functions for each firm. Thus, profits for the respective firms are modified as follows:

$\Pi_{A}=\left(1-\alpha^{c}\right)\left(R_{A}-c\right) \mathcal{F}(\bar{X})+\alpha^{c}\left\{\left(R_{A}-c\right) \mathcal{F}\left(X_{S}\right)-\left(d_{A}+z\right)\left(\mathcal{F}\left(X_{S}\right)-\mathcal{F}\left(X_{A}\right)\right)\right\}$,

$\Pi_{B}=\left(1-\alpha^{c}\right)\left(R_{B}-c\right)(1-\mathcal{F}(\bar{X}))+\alpha^{c}\left\{\left(R_{B}-c\right)\left(1-\mathcal{F}\left(X_{S}\right)\right)-\left(d_{B}+z\right)\left(\mathcal{F}\left(X_{B}\right)-\mathcal{F}\left(X_{S}\right)\right)\right\}$, where the first (second) term in each profit function is the net profit from Non-Users (C-Users). Assuming both firms target coupons, the subgame perfect equilibrium is then characterized by the following first order conditions:

$$
\frac{\partial \Pi_{A}}{\partial R_{A}}=\alpha^{c}\left\{\mathcal{F}\left(X_{S}\right)+\left(R_{A}-c\right) f\left(X_{S}\right) \frac{\partial X_{S}}{\partial R_{A}}-\left(d_{A}+z\right)\left(f\left(X_{S}\right) \frac{\partial X_{S}}{\partial R_{A}}-f\left(X_{A}\right) \frac{\partial X_{A}}{\partial R_{A}}\right)\right\}+
$$

$$
\left(1-\alpha^{c}\right) \mathcal{F}(\bar{X})+\left(1-\alpha^{c}\right)\left(R_{A}-c\right) f(\bar{X}) \frac{\partial \bar{X}}{\partial R_{A}}=0
$$

$\frac{\partial \Pi_{A}}{\partial d_{A}}=\alpha^{c}\left\{\left(R_{A}-c\right) f\left(X_{S}\right) \frac{\partial X_{S}}{\partial d_{A}}-\left(\mathcal{F}\left(X_{S}\right)-\mathcal{F}\left(X_{A}\right)\right)-\left(d_{A}+z\right)\left(f\left(X_{S}\right) \frac{\partial X_{S}}{\partial d_{A}}-f\left(X_{A}\right) \frac{\partial X_{A}}{\partial d_{A}}\right)\right\}+$

$$
\left(1-\alpha^{c}\right)\left(R_{A}-c\right) f(\bar{X}) \frac{\partial \bar{X}}{\partial d_{A}}=0
$$

$\frac{\partial \Pi_{B}}{\partial R_{B}}=\alpha^{c}\left\{1-\mathcal{F}\left(X_{S}\right)-\left(R_{B}-c\right) f\left(X_{S}\right) \frac{\partial X_{S}}{\partial R_{B}}-\left(d_{B}+z\right)\left(f\left(X_{B}\right) \frac{\partial X_{B}}{\partial R_{B}}-f\left(X_{S}\right) \frac{\partial X_{S}}{\partial R_{B}}\right)\right\}+$

$$
\begin{gathered}
\left(1-\alpha^{c}\right)(1-\mathcal{F}(\bar{X}))-\left(1-\alpha^{c}\right)\left(R_{B}-c\right) f(\bar{X}) \frac{\partial \bar{X}}{\partial R_{B}}=0 \\
\frac{\partial \Pi_{B}}{\partial d_{B}}=-\alpha^{c}\left\{\left(R_{B}-c\right) f\left(X_{S}\right) \frac{\partial X_{S}}{\partial d_{B}}+\left(\mathcal{F}\left(X_{B}\right)-\mathcal{F}\left(X_{S}\right)\right)+\left(d_{B}+z\right)\left(f\left(X_{B}\right) \frac{\partial X_{B}}{\partial d_{B}}-f\left(X_{S}\right) \frac{\partial X_{S}}{\partial d_{B}}\right)\right\}- \\
\left(1-\alpha^{c}\right)\left(R_{B}-c\right) f(\bar{X}) \frac{\partial \bar{X}}{\partial d_{B}}=0 .
\end{gathered}
$$

Let the symmetric solution be given by $\tilde{R}_{A}=\tilde{R}_{B}=\tilde{R}$, and $\tilde{d}_{A}=\tilde{d}_{B}=\tilde{d}$. This means that $X_{S}=\bar{X}=1 / 2$, and $X_{A}=1-X_{B}$. Since the first order conditions for firms $A$ and $B$ are identical, the above system of equations can be reduced to the following two identities:

$$
\begin{aligned}
\frac{1}{2}-\frac{f\left(\frac{1}{2}\right)}{2 t^{w}}(\tilde{R}-c)-\frac{\alpha^{c}}{2 t^{c}}\left\{f\left(\frac{t^{c}-\tilde{d}}{2 t^{c}}\right)-f\left(\frac{1}{2}\right)\right\}(\tilde{d}+z) & \equiv 0, \\
\frac{f\left(\frac{1}{2}\right)}{2 t^{c}}(\tilde{R}-\tilde{d}-c-z)-\frac{1}{2}+\mathcal{F}\left(\frac{t^{c}-\tilde{d}}{2 t^{c}}\right) & \equiv 0 .
\end{aligned}
$$


Totally differentiating the above two identities with respect to $z$ and evaluating the resulting two identities at $\tilde{z}$ such that the firms are just indifferent between targeting and not targeting $(\tilde{d}=0)$,

we have:

$$
\begin{aligned}
&-\frac{f\left(\frac{1}{2}\right)}{2 t^{w}} \frac{d \tilde{R}}{d z} \equiv 0, \\
& \frac{f\left(\frac{1}{2}\right)}{2 t^{c}} \frac{d \tilde{R}}{d z}-\frac{f\left(\frac{1}{2}\right)}{t^{c}} \frac{d \tilde{d}}{d z}-\frac{f\left(\frac{1}{2}\right)}{2 t^{c}} \equiv 0 .
\end{aligned}
$$

Solving yields $d \tilde{R} / d z=0$ and $d \tilde{d} / d z=-1 / 2$. This means that equilibrium regular prices do not change in the neighborhood of $z$ for which coupon targeting just emerges in equilibrium.

To verify that coupon targeting leads to a prisoner's dilemma, substitute $\left(\tilde{R}_{A}, \tilde{R}_{B}, \tilde{d}_{A}, \tilde{d}_{B}\right)$ into $\Pi_{A}$ and $\Pi_{B}$ and differentiate with respect to $z$ to give

$$
\frac{d \Pi_{i}}{d z}=\frac{\partial \Pi_{i}}{\partial R_{i}} \frac{d \tilde{R}_{i}}{d z}+\frac{\partial \Pi_{i}}{\partial d_{i}} \frac{d \tilde{d}_{i}}{d z}+\frac{\partial \Pi_{i}}{\partial R_{-i}} \frac{d \tilde{R}_{-i}}{d z}+\frac{\partial \Pi_{i}}{\partial d_{-i}} \frac{d \tilde{d}_{-i}}{d z}+\frac{\partial \Pi_{i}}{\partial z} .
$$

Substituting in $d \tilde{R}_{i} / d z=d \tilde{R}_{-i} / d z=0$ and $d \tilde{d}_{i} / d z=d \tilde{d}_{-i} / d z=-1 / 2$, and noting that $\partial \Pi_{i} / \partial d_{i}=0$ by the envelope theorem, we have

$$
\frac{d \Pi_{A}}{d z}=\frac{d \Pi_{B}}{d z}=\frac{\alpha^{c}(\tilde{R}-c) f\left(\frac{1}{2}\right)}{4 t^{c}}>0 .
$$

This means that equilibrium firm profits necessarily decrease in the neighborhood of $z$ for which coupon targeting just emerges in equilibrium.

\section{Appendix E}

In this appendix, we show the robustness of our results to any pair of symmetric firm locations, $\tilde{a}$ and $\tilde{b}$, for which a pure strategy Nash equilibrium exists with $C$-Users in all five regions. ${ }^{27}$ Since the proof for the case with mass-media couponing is analogous to the case without mass-media couponing, we focus exclusively on the latter and leave details of the other to the reader.

${ }^{27}$ As is well known (see d'Aspremont et al., 1979), pure strategy Nash pricing equilibria do not exist if $\tilde{a}$ and $\tilde{b}$ are sufficiently close. For example, in the standard Hotelling model with linear transport costs, a pure strategy Nash firm's demand that arises with linear transportation costs; if firm B (A) succeeds in obtaining the patronage of a consumer located at $\tilde{a}(\tilde{b})$, it also necessarily captures all consumers located in the interval $[0, \tilde{a}]([\tilde{b}, 1])$.
Note that whenever there are equilibria with $C$-Users in all five regions, the definitions of $X_{A}$, $X_{B}$, and $X_{S}$ are unaffected by the fact that the two firms are now located away from the two ends. Since $X_{A}>\tilde{a}$ and $X_{B}<\tilde{b}$ in any such equilibria, firms' targeting strategies and payoff functions also remain unchanged. Therefore, the necessary conditions characterizing such an equilibrium are the same as if the two firms located at both ends and, consequently, so is the candidate equilibrium. Now, we need only to show that such an equilibrium indeed exists, given that the two firms are located symmetrically away from the two ends.

Consider, without loss of generality, firm A's possible deviations. Given $\tilde{R}_{B}=t^{w}+c$ and $\tilde{d}_{B}=\left(t^{w}-z\right) / 2$, firm $A$ can either deviate by choosing $\left(R_{A}, d_{A}\right)$ such that it has no $C$-Users in region I or it can deviate by choosing $\left(R_{A}, d_{A}\right)$ such that it captures all of firm B's $C$-Users. In the former case, the optimal deviation for firm $A$ is given by:

$$
\left(\hat{R}_{A}, \hat{d}_{A}\right)=\arg \max _{R_{A}, d_{A}}\left(1-\alpha^{c}\right)\left(R_{A}-c\right) \bar{X}+\alpha^{c}\left(R_{A}-d_{A}-c-z\right) X_{S}
$$

s.t. $X_{A} \leq \tilde{a}$ and $d_{A} \geq 0$.

In the latter case, it is given by:

$$
\begin{aligned}
\left(\hat{R}_{A}, \hat{d}_{A}\right)= & \arg \max _{R_{A} d_{A}}\left(1-\alpha^{c}\right)\left(R_{A}-c\right) \bar{X}+\alpha^{c}\left\{\left(R_{A}-c\right) X_{A}+\left(R_{A}-d_{A}-c-z\right)\left(1-X_{A}\right)\right\} \\
\text { s.t. } & X_{S}=\tilde{b} \text { and } d_{A} \geq 0 .
\end{aligned}
$$

Straightforward calculations show it is never profitable for firm A to take the first path. In the latter case, the profitability of firm A's deviation is decreasing in $\tilde{b}$. At $\tilde{b}=\frac{3}{4}$, it can be shown that firm A cannot profitably deviate. Since firm B's deviation is symmetric, we conclude that, for $\tilde{b} \geq \frac{3}{4}$ and $\tilde{a} \leq \frac{1}{4}$, the subgame perfect equilibrium exists as stated in figure 3 in the text..$^{28}$

${ }^{28}$ The exact cutof points at which $\tilde{a}$ and $\tilde{b}$ make firms A and B just indifferent to deviating are implicitly defined by a complex expression of several parameters. 


\section{Bibliography}

Alsop, Ronald (1985), "Companies See Ways to Put Coupons Where They'll Count," Wall Street Journal, August 8.

Babakus, Emin, Peter Tat and William Cunningham (1988), "Coupon Redemption: a Motivational Perspective," Journal of Consumer Marketing, 5, 37-43.

Blattberg, Robert C. and Scott A. Neslin (1990), Sales Promotion: Concepts, Methods, and Strategies, NJ: Prentice Hall, Inc.

Borenstein, Severin (1985), "Price Discrimination in Free-Entry Markets," Rand Journal of Economics, 16, 380-397.

Brumback, Nancy (1994), "Implements of Influence; Electronic Merchandising Tools; Supermarket Technology, ${ }^{n}$ Supermarket News, February 28, p. 25.

Business Week (1989), "Stalking the Consumer." August 28, 54-62.

Chiang, Jeongwen (1992) "Competing Coupon Promotions-A Zero Sum Game?" Washington University in St. Louis, mimeo.

d'Aspremont, Claude, J. Jaskold Gabszewicz and J.F. Thisse (1979), "On Hotelling's Stability in Competition," Econometrica, 47, 1145-1150.

Gerstner, Eitan and James Hess (1991a), "A Theory of Channel Price Promotions." American Economic Review, 81, 872-886.

- and - (1991b), "Who Benefits from Large Rebates: Manufacturer, Retailer, or Consumer?" Economics Letters, 36, 5-8.

Holmes, Thomas (1989), "The Effects of Third Degree Price Discrimination in Oligopoly," American Economic Review, 79, 244-250.

Hotelling, Harold (1929), "Stability in Competition." Economic Journal, 39, 41-57.

Houston, Douglas A. and John S. Howe (1985), "An Economic Rationale for Couponing.” Quarterly Journal of Business and Economics, 24, 37-49.
Jeuland, Abel and Chakravarthi Narasimhan (1985), "Dealing-Temporary Price Cuts-by Seller as a Buyer Discrimination Mechanism," Journal of Business, 58, 295-308.

Klein, Robert (1985), "How to Use Research to Make Better Sales Promotion Marketing Decisions." in S. Ulanoff [ed.], Handbook of Sales Promotions, NY: McGraw Hill, 457-466.

Levedahl, William (1984), "Marketing, Price Discrimination, and Welfare: Comment." Southern Economic Journal, 50, 886-891.

Litwak, David (1991), "Electronic Marketing: Not Yet on Target, But Coming Into Focus," Supermarket Business, February, p. 35.

Mayer, Martin (1990), "Scanning the Future," Forbes, October 15, 114-117.

Millstein, Marc (1989), "Electronic Marketing Set to Take Off in 1990's," Supermarket News, 39, No. 41 , p. 33.

Moorthy, K. Sridhar (1985), "Using Game Theory to Model Competition," Journal of Marketing Research, 22, 262-282.

Narasimhan, Chakravarthi (1984), “A Price Discrimination Theory of Coupons." Marketing Science, 3, 128-147.

- (1988), "Competitive Promotional Strategies." Journal of Business, 61, 427-449.

NCH Promotional Services (1992), Coupon Distribution and Redemption Patterns, Chicago, Illinois.

Neslin, Scott A. (1990), "A Market Response Model for Coupon Promotions." Marketing Science, 9, 125-145.

Neslin, Scott A. and Darral G. Clarke (1987), "Relating the Brand Use Profile of Coupon Redeemers to Brand and Coupon Characteristics." Journal of Advertising Research, 27, 23-32.

Raju, Jagmohan, Srinivasan, V. and Rajiv Lal (1990), "The Effects of Brand Loyalty on Competitive Price Promotional Strategies," Management Science, 36, 276-304.

Rao, Ram (1991), "Pricing and Promotions in Asymmetric Duopolies." Marketing Science, 10, 131-144. 
Raphel, Murray (1988a), "How Am I Gonna Fight the Competition Blues," Direct Marketing, 51, $142-146$.

— (1988b), "How Four Cards Made a Full House." Direct Marketing, 51, 92-95.

Reibstein, David J. and P. Traver (1982), "Factors Affecting Coupon Redemption Rates," Journal of Marketing, 46, 102-113.

Rossi, Peter E. and Greg M. Allenby (1993), "A Bayesian Approach to Estimating Household Parameters," Journal of Marketing Research, 30, 171-182.

Salop, Steven C. (1977), "The Noisy Monopolist: Imperfect Information, Price Dispersion and Price Discrimination," Review of Economic Studies, 44, 393-406.

Shoemaker, Robert W. and V. Tibrewala (1985), "Relating Coupon Redemption Rates to Past Purchasing of the Brand," Journal of Advertising Research, 25, 40-47.

Sweeney, George (1984), "Marketing, Price Discrimination, and Welfare: Comment." Southern Economic Journal, 50, 892-899.

Ward, Ronald and James Davis (1978), "Coupon Redemption," Journal of Advertising Research, 62, 393-401. 

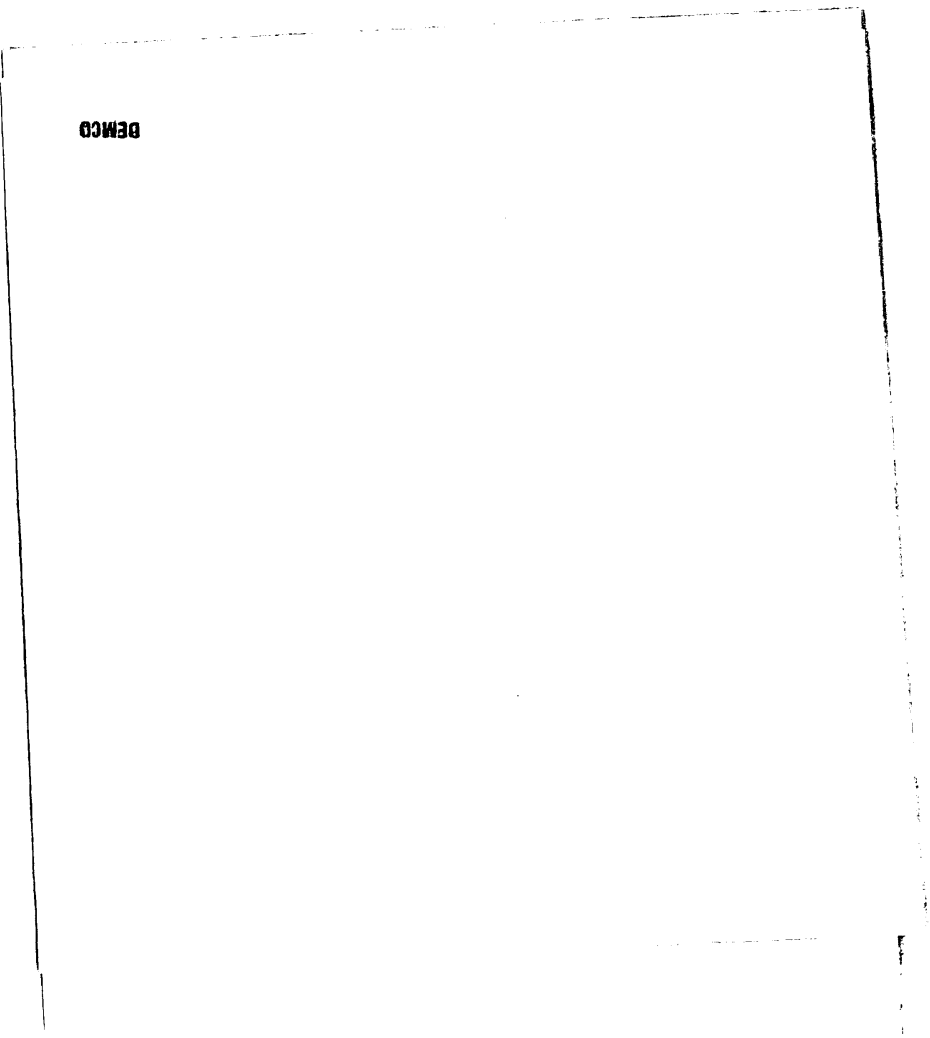
